\title{
87th Annual Meeting of the American Thyroid Association October 18-22, 2017, Victoria, British Columbia, Canada
}

\author{
Angela M. Leung and Mingzhao Xing
}

W E ARE EXCITED THAT THE 87th annual meeting of the American Thyroid Association (ATA) is almost upon us! On behalf of the Program Committee, we look forward to welcoming attendees and their guests to the annual meeting that will be held October 18-22, 2017, at the Fairmont Empress and Victoria Conference Centre in Victoria, British Columbia, Canada. Over this past year, the committee, comprised of experts from all thyroid disciplines, has thoughtfully worked to put together a program featuring the latest advances in basic, translational, and clinical thyroidology.

This year, the program will not only feature stimulating plenary lectures, symposia, discussion-debates, and meetthe-professor sessions that past attendees have highly enjoyed, but also debut several new session formats that we hope will be of great interest to conference attendees. Of particular interest, the annual meeting committee this year is proud to debut a concurrent pediatric thyroid satellite meeting, the ATA Pediatric Thyroid Forum, entitled "Update on Pediatric Thyroid Disease 2017-Current State and Future Directions" to be moderated by Andrew Bauer, MD. We hope that this novel satellite meeting will be a unique recurring opportunity for our pediatric thyroid colleagues to engage in sessions with specific relevance to their clinical and research interests.

The pre-meeting activities will begin with the ATA Advanced Endocrine Neck Ultrasound Course, which will run in parallel with the E. Chester Ridgway Trainee Conference for clinical, surgical, pediatric endocrine, and basic science trainees. That evening, the annual meeting will kick off with a Year in Thyroidology review featuring three leaders to discuss the top recent manuscripts published in basic, clinical, and surgical thyroidology. Carmelo Nucera, MD, PhD, Gregory Brent, MD, and Julie Ann Sosa, MD, will present the studies in these fields, respectively, for this highly anticipated opening session.

The two distinguished plenary lecturers of the annual meeting will be Weiping Teng, MD, PhD, of the First Affiliated Hospital of China Medical University, who will present "Iodine Intake and Thyroid Diseases: Learnings in China," and John Cambier, PhD, of the University of Colorado Anschutz Medical Campus, who will speak on "Understanding How Breaches in Immune Tolerance Lead to Autoimmune Thyroid Disease."
The ATA will announce the recipient of the 2017 Van Meter Award at the meeting, and the winner, recognized for outstanding contributions to research on the thyroid or related subjects, will present the Van Meter Award Lecture. The recipient of the 2017 Paul Starr Award lecture is Quan-Yang Duh, MD, recognized for his outstanding contributions to clinical thyroidology, while Julie Ann Sosa, MD, will deliver the 2017 Lewis E. Braverman Lectureship with a talk entitled "Re-Telling the Story About Thyroid Cancer-Rising Incidence, Mortality, and Maybe an Explanation.' This year's Sidney H. Ingbar Award Lecture is "Genomic Evolution of Thyroid Nodules and Cancer-New Answers to Old Questions" to be delivered by Yuri Nikiforov, MD, PhD. The ATA will also present the John B. Stanbury Thyroid Pathophysiology Medal and the 2016 Distinguished Service Award to James Fagin, MD, and Bryan Haugen, MD, respectively.

Several informative symposia will take place throughout the meeting, including the topic of "New Directions in Thyroid Nodules and Thyroid Cancer,' featuring presentations on the updated Bethesda System for Reporting Thyroid Cytopathology, the newest edition of the American Joint Committee on Cancer thyroid cancer staging criteria, and extent of thyroid surgery in moderately-sized thyroid cancers. New this year is a "Thyroid Dysfunction Grand Rounds," moderated by Mary Samuels, MD, that will be paneled by five experts regarding the diagnostic and management aspects of hypo- and hyperthyroidism. Basic thyroid research symposia will feature innovative topics that include "Thyroid Hormone Transporters," featuring presentations on the role of thyroid hormone receptors in the brain and novel clinical translational approaches, and "Novel Molecular Mechanisms in Thyroid Cancer," featuring presentations on nuclear receptor signaling and novel genetic mechanisms in benign and malignant thyroid tumors. Other basic research symposia will feature presentations bringing new mechanistic insights into the roles of the thyrotropin receptor and micro-RNAs in benign and malignant thyroid diseases, respectively.

The annual meeting again offers attendees the opportunity to engage directly with colleagues and trainees at their posters and oral abstract presentations. There are a record number of submitted abstracts at this year's meeting, a testament to researchers desiring to present their best work

2017 ATA Annual Meeting Co-Chairs. 
among this audience, and we encourage your support in visiting the posters and attending the oral abstract sessions. The program will also highlight presentations by the recent ATA Research Grant recipients. This year's awardees are investigating research topics that include the genetics of advanced thyroid cancer, mouse modeling of medullary thyroid carcinoma, and the role of the renal sodium-iodide symporter in iodide metabolism and thyroid function.

New to the program this year will also be an informative session featuring highlights from Video Endocrinology, one of the three flagship journals of the ATA. This new format will include published video presentations on the topics of lateral and central neck dissections in thyroid cancer, as well as remote access thyroid surgery. A series of discussiondebates and meet-the-professor sessions to be held throughout the meeting will focus on the most recent advances in topics that include thyroid hormone assays and therapy, thyroid disease in pregnancy, thyroid epidemiology, quality of life issues in thyroidology, thyroidal environmental toxicants, and thyroid cancer. The thyroid tumor board on the final day of the meeting will be moderated by Manisha Shah, $\mathrm{MD}$, and, as always, present one last opportunity to be challenged by the presentation of interesting cases for discussion among our distinguished panelists.

Equally as important as the chance to hear the latest research and advances in thyroidology, the meeting will allow for opportunities to engage in informal interaction. We encourage you to meet with presenters and attendees with expertise in basic and clinical thyroidology, general endocrinology, endocrine surgery, otolaryngology, medical oncology, nuclear medicine, laboratory sciences, industry, pathology, and the allied health disciplines. The program offers the opportunity for ample networking at the opening reception, ATA annual banquet, or one of the many scheduled breaks over the five days. There are additional opportunities to receive relevant information during the ATA annual meeting, including the chance to meet with pharmaceutical, device, and technology sponsors at the 2017 Thyroid EXPO. The ATA Alliance for Patient Education Public Forum will again be an open opportunity for the public to meet with thyroid experts and panelists in this engaging session. For further information about the 87th annual meeting of the ATA, please visit the meeting webpage at www.thyroid.org.

Finally, hailed as the internationally renowned "City of Gardens," Victoria offers a breathtaking environment to convene with friends and colleagues for the annual meeting. The Victoria Conference Centre and historic hotel headquarters, The Fairmont Empress, are perfectly situated on the Inner Harbour, one of the most beautiful in the world.

We look forward to seeing you at the 87 th annual meeting of the ATA! 